\title{
Millimeter wave treatment inhibits NO-induced apoptosis of chondrocytes through the p38MAPK pathway
}

\author{
XIHAI LI ${ }^{1}$, MIN DU ${ }^{2}$, XIANXIANG LIU ${ }^{1}$, MINGXIA WU ${ }^{1}$, HONGZHI YE ${ }^{1}$, \\ JIUMAO LIN $^{1}$, WENLIE CHEN ${ }^{1}$ and GUANGWEN WU ${ }^{1}$ \\ ${ }^{1}$ Huatuo, University Town, Minhou Shangjie, Fujian University of Traditional Chinese Medicine, Fuzhou, \\ Fujian 350108; ${ }^{2}$ Institute of Precision Instruments, Fuzhou University, Fuzhou 350002, P.R. China
}

Received October 19, 2009; Accepted December 7, 2009

DOI: $10.3892 /$ ijmm_00000357

\begin{abstract}
In the present study, we investigated the effects of millimeter wave treatment on the activation of the p38MAPK signaling pathway in the process of NO-induced apoptosis in chondrocytes. Cartilage was isolated from the knee joint of SD rats and used to establish cultured primary chondrocytes. After identification using in situ staining of type II collagen, the passage 2 chondrocytes were incubated with or without sodium nitroprussiate (SNP) to induce apoptosis and treated with a millimeter wave for various times. The apoptosis of chondrocytes was detected using immunofluorescence, an MTT assay, and Annexin V-FITC labeling followed by fluorescence-activated cell sorting (FACS). The activity of caspase- 3 was measured using colorimeters, and the levels of p38 and p53 were also detected using RT-PCR and Western blotting. After treatment with SNP, the OD values of the experimental groups were significantly lower than the control group $(\mathrm{P}<0.01)$. The 24 -h interference of a millimeter wave significantly prevented apoptosis $(\mathrm{P}<0.01)$ and showed a dose dependency, and an identical trend of apoptosis was noted with normal cell number counting $(\mathrm{P}<0.01)$ and FACS $(\mathrm{P}<0.01)$. Consistently, the caspase 3 activity showed a reverse trend, with the highest activity in the experimental group receiving no millimeter wave treatment $(\mathrm{P}<0.01)$. The mRNA expression of p38 and p53 and the protein levels of phosphorylated p38 and p53 showed a similar trend $(\mathrm{P}<0.01)$ to that of caspase 3 activity. In conclusion, millimeter wave treatment inhibits the SNP-induced apoptosis of chondrocytes through the p38MAPK pathway.
\end{abstract}

\section{Introduction}

Apoptosis (also called programmed cell death) is a form of active cell death regulated by multiple genes. Under normal conditions, chondrocytes undergo spontaneous apoptosis,

Correspondence to: Dr Xianxiang Liu, Fujian University of Traditional Chinese Medicine, Fuzhou 350108, P.R. China

E-mail: liuxianxiang@163.com

Key words: apoptosis, chondrocytes, osteoarthritis which is required for the maturation and morphological maintenance of the cartilage (1). Excessive chondrocyte apoptosis leads to a decrease in chondrocyte number and the extracellular matix (ECM), breaks the balance of enzymatic systems for synthesis and degradation of ECM, and disrupts the amount and distribution of ECM. Conversely, these changes in ECM increase chondrocyte apoptosis, and eventually this feedback leads to the degeneration of cartilage $(2,3)$.

Mitogen-activated protein kinase (MAPK) is a serine/ threonine kinase whose signaling cascade is a major pathway for extracellular signals to stimulate cell proliferation with important roles in cell growth, proliferation, differentiation, and apoptosis $(4,5)$. p38 can be activated, specifically phosphorylated, by a series of inflammatory factors and stimuli from the environment. Phosphorylated p38 is then shuttled into the nucleus where it activates transcription factors, initiates expression of upstream apoptosis-related genes including p53, and promotes the apoptosis of chondrocytes $(6,7) \cdot \mathrm{p} 53$ is a nuclear phosphorylated protein of $53 \mathrm{kDa}$ and is an important regulator of DNA damage and the cell cycle that negatively controls cell proliferation and promotes apoptosis $(8,9)$. Caspase- 3 is a key member of the caspase family that executes an apoptotic signal at the end of the signaling cascade. Once activated, caspase- 3 can cleave DNA repair proteins (such as PARP), cytoskeletal proteins and iCAD (inhibitor of caspase-activated deoxytribonuclease), thereby leading to the fragmentation of DNA and eventually cell death (10). Conceivably, blocking p38 signaling may effectively inhibit these negative effects and prevent chondrocyte apoptosis and promote cartilage repair.

A millimeter wave is a electromagnetic wave with a wavelength between 1 and $10 \mathrm{~mm}$ and a frequency of 30$300 \mathrm{GHz}$. It has been shown that a millimeter wave can evoke multiple biological effects, both locally and globally. Organisms produce coherent oscillations at $0.5 \times 10^{10}$ to $3 \times 10^{12}$ during metabolism, and the frequency of a millimeter wave is in the same range. Therefore, the energy of a millimeter wave can be absorbed by the organism through resonance. In turn, the energy can be transferred to interfere with signal transduction in the organism and dynamically regulate metabolism (11-13). Our previous study showed that millimeter wave treatment induced the directed differentiation of mesenchymal stem cells (MSCs) to chondrocytes 
through upregulating the mRNAs of Cbfa1 and Sox 9 and ultimately the levels of glycosaminoglycan and type II collagen (14).

Nitric oxide (NO) is an important physiological and pathological signaling molecule. It can be produced by inflammatory stimuli, an exogenous donor such as sodium nitroprussiate (SNP) and nitroso compounds (NOC). It can inhibit the proliferation of chondrocytes, induce chondrocyte apoptosis, and thereby damage cartilage and impair joint cartilage repair (15). NO can induce chondrocyte apoptosis through multiple pathways including the p38MAPK pathway. In this study, we used cultured chondrocytes from the joint cartilage of SD rats as a model to study the effects of a millimeter wave signal on NO-induced apoptosis and p38MAPK signaling.

\section{Materials and methods}

Reagents and equipment. The reagents used in this study included fetal bovine serum (FBS), Dulbecco's modified Eagle's medium (DMEM), trypsin and Hoechst 33342 from Invitrogen Inc. (Carlsbad, CA, USA); MTT, type-II collagenase and sodium nitroprussiate (SNP) from Sigma (NJ, USA); a caspase-3 activity measuring kit from Bio Vision (Lakewood, NJ, USA); antibodies against phosphop38, p53, and B-actin from Santa Cruz (Santa Cruz, CA, USA); PVDF membrane from Millipore (NJ, USA); a caspase3 activity measuring kit from Bio Vision (Lakewood, NJ, USA); a type II collagen immunostaining kit and Annexin VFITC kit from Boster Inc. (Wuhan, Hubei, China); a total protein extraction kit from Nanjing KeyGen Biotech (Nanjing, Jiangsu, China); HRP-secondary rabbit anti-goat antibody from Zhongshan Goldenbridge Biotech (Beijing, China); and an ECL kit from Beyotime Biotech (Nanjing, Jiangsu, China).

Equipment included a fluorescent microscope from Olympus (Japan), $\mathrm{CO}_{2}$ incubator from Heraeus (Germany), FACS caliber from BD (USA), plate reader from Bio-Tek (USA), 9600 DNA amplifier from PE (USA) and Gel doc 2000 from GE (USA). The millimeter wave signal was generated using the KFA-100A millimeter therapeutics from Beijing Zhongkang Inc. The wavelength range was $7.5-10.0 \mathrm{~mm}$, the power density was $4 \mathrm{mw} / \mathrm{cm}^{2}$, and the radiating area was $33.2 \pm 3 \mathrm{~mm} \times 45.6 \pm 4 \mathrm{~mm}$.

Animals. Male Sprague-Dawley (SD) rats, 3 weeks of age, $(n=54)$ were purchased from the Super-BK Laboratory Animal Inc. (Shanghai, China). The study protocol was approved by the Fujian University of Traditional Chinese Medicine.

Isolation, culture, and identification of rat chondrocytes. Healthy SD rats were sacrificed by cervical dislocation, and the knee joints were dissected out under sterile conditions. The cartilage was cut out, rinsed with PBS containing penicillin and streptomycin 3 times, and washed with DMEM medium 3 times. The cartilage was cut into $1-\mathrm{mm}^{3}$ pieces and incubated in $0.2 \%$ type II collagenase in a flask at $37^{\circ} \mathrm{C}$ in $5 \% \mathrm{CO}_{2}$. For every $45 \mathrm{~min}$, the supernatant was collected and spun at $1000 \mathrm{rpm}$ for 5 min to collect a cell pellet. After 4 cycles of medium change, all of the cell pellets were resuspended in DMEM complete medium (containing $10 \%$ FBS, $50 \mathrm{mg} / \mathrm{l}$ vitamin C, $100 \mathrm{U} / \mathrm{ml}$ penicillin, and $100 \mathrm{U} / \mathrm{ml}$ streptomycin), filtered through a $200-\mu \mathrm{m}$ cell strainer, seeded at $2-3 \times 10^{5} / \mathrm{ml}$ and incubated at $37^{\circ} \mathrm{C}$ in $5 \% \mathrm{CO}_{2}$. The cells were labeled as F0. After $72 \mathrm{~h}$, the medium was changed, and the medium was changed every 3 days thereafter. The cells were observed every day and were passaged when they reached $80 \%$ confluence.

The passage 2 chondrocytes were seeded on glass cover slips, washed with PBS, and fixed in $4 \%$ paraformaldehyde for $30 \mathrm{~min}$. After treatment with $\mathrm{H}_{2} \mathrm{O}_{2}$ at room temperature for $30 \mathrm{~min}$ and digestion with pepsin to expose the mRNA, the slips were post-fixed in $1 \%$ neutral formaldehyde for $10 \mathrm{~min}$, pre-hybridized at $40^{\circ} \mathrm{C}$ for $4 \mathrm{~h}$, and hybridized at $40^{\circ} \mathrm{C}$ overnight (type II collagen target sequences: $5^{\prime}$-TCCCC AGTCG CTGGT GCTGC TGACG CTGCT-3', 5'-CATCG ACATG TCAGC CTTTG CTGGC TTAGG-3', 5'-CCATG CAGTA CATGC GGGCC GACAG GGCAG-3'). After washing, the hybridization signals on the slips were detected using anti-digoxin antibody followed by DAB and hematoxylin staining. The slides in the negative controls were restained with hematoxylin free from hybridization solution. The slides were observed, and images were captured using the HMIAS-2000 analyzer. For each slide, 10 fields were randomly selected, and the relative density of the staining signal was analyzed.

Cell treatment and grouping. After the second passage, chondrocytes were seeded and cultured for $72 \mathrm{~h}$, cells were randomly divided into 3 groups, and the medium was changed to complete medium containing $0,0.5,1$, or $2 \mathrm{mM}$ SNP and further cultured for $24 \mathrm{~h}$. The induced apoptosis and morphological changes in cells were observed under a microscope.

The passage 2 chondrocytes were seeded at $1 \times 10^{5} / \mathrm{ml}$ in a T-25 flask and incubated for $72 \mathrm{~h}$. The cells were then randomly divided into 4 groups: control group (normal culture without treatment); experimental group 1 (treated with $1 \mathrm{mM}$ SNP and receiving no millimeter wave signal); experimental group 2 (treated with $1 \mathrm{mM}$ SNP and receiving a millimeter wave signal 3 times at $30 \mathrm{~min}$ per $8 \mathrm{~h}$, the total duration of millimeter wave was $90 \mathrm{~min}$ ); and experimental group 3 (treated with $1 \mathrm{mM} \mathrm{SNP}$ and receiving a millimeter wave signal 3 times at $60 \mathrm{~min}$ per $8 \mathrm{~h}$, the total duration of millimeter wave lasting $180 \mathrm{~min}$ ). After a 30 -min millimeter wave radiation, the detecting head of the millimeter wave was hung above the interference cells at a height of $30 \mathrm{~mm}$, once all of the interference cells were collected in the detecting head-centered circle with a radius of $20 \mathrm{~mm}$, which fell within the radiation area of $33.2 \pm 3 \mathrm{~mm} \times 45.6 \pm 4 \mathrm{~mm}$. After treatment, the cells were observed under a microscope, and apoptosis was detected using Hoechst 33342 staining, MTT assay, and Annexin V-FITC staining followed by FACS. The cells were also processed to measure the activity of caspase-3, mRNA levels of p38 and p53, and the protein levels of phospho-p38 and p53.

Hoechst 33342 staining. After treatment with SNP and with or without millimeter wave signal, the chondrocytes were fixed in $4 \%$ neutral formaldehyde for $15 \mathrm{~min}$, washed with PBS for 
5 min, and stained with $10 \mu \mathrm{M}$ Hoechst 33342 at $37^{\circ} \mathrm{C}$ for 15 min protected from light. After being washed with PBS, the cells were observed under a fluorescent microscope. For every group, 10 fields were randomly selected, and the apoptotic cells were counted and analyzed.

MTT assay. The passage 2 chondrocytes were seeded in a 96well plate at $1 \times 10^{4} / \mathrm{ml}$, cultured for $72 \mathrm{~h}$, and treated with SNP and a millimeter wave signal. The chondrocytes were then washed with PBS once, plus $20 \mu 1$ of $0.5 \%$ MTT solution. After incubation at $37^{\circ} \mathrm{C}$ for $4 \mathrm{~h}$, the wells were supplied with $150 \mu 1$ of DMSO and shaken for $10 \mathrm{~min}$. The OD570 was analyzed on a plate reader.

Fluorescence-activated cell sorting (FACS). FACS was performed according to the manufacturer's procedure. After treatment with SNP and millimeter wave signal, chondrocytes were trypsinized, washed with PBS, and resuspended at $1 \times 10^{6} / \mathrm{ml}$. The cell suspension $(100 \mu \mathrm{l})$ was incubated with $5 \mu 1$ of Annexin V/FITC and $10 \mu 1 \mathrm{PI}(20 \mu \mathrm{g} /$ $\mathrm{ml}$ ) at room temperature for $15 \mathrm{~min}$ protected from light. After repletion with $400 \mu \mathrm{l}$ of PBS, $10^{4}$ cells were run through FACS caliber and counted for the apoptosis rate.

Colorimetric assay for caspase-3 activity. The passage 2 chondrocytes were seeded in a 6 -well plate at $2 \times 10^{5} / \mathrm{ml}$, cultured for $72 \mathrm{~h}$, and treated with SNP and millimeter wave signal. Total protein was then extracted, and the protein concentration was measured using the BCA method. To produce the reaction mixture, $50 \mu \mathrm{l}$ of cell lysates $(100 \mu \mathrm{g}$ protein) was mixed with $50 \mu 1$ of $2 \mathrm{X}$ reaction buffer and $5 \mu \mathrm{l}$ of $4 \mathrm{mM}$ DEVD-pNA substrate and incubated at $37^{\circ} \mathrm{C}$ for $2 \mathrm{~h}$. The OD405 was measured using an ELX800 plate reader.

$R T-P C R$. Total RNA was extracted using Trizol reagents from the treated cells according to the standard protocol. One microgram of RNA was reverse transcribed into cDNA, which was used in the PCR amplification for p38 (275 bp, sense 5'-GCC GAG ATG CTA ACC-3', antisense 5'-TGA GCG AGT GCC TGA-3') and p53 (232 bp, sense 5'-GCG TTG CTC TGA TGG TGA-3', antisense 5'-CAG CGT GAT GAT GGT AAG GA-3'). ß-actin (390 bp, sense 5'-GAT GGG AAG TGC TGG ATA G-3', antisense 5'-TTG TGA TGT TTC GGA TGG-3') was used as the internal standard. The PCR condition was as follows: one cycle at $95^{\circ} \mathrm{C}$ for $5 \mathrm{~min}$ and 30 cycles at $95^{\circ} \mathrm{C}$ for $30 \mathrm{sec}, 52 / 55 / 56^{\circ} \mathrm{C}$ for $30 \mathrm{sec}$, and $72^{\circ} \mathrm{C}$ for $30 \mathrm{sec}$. The amplified products were separated on a $1.5 \%$ agarose gel and analyzed. The density of p38, p53 and B-actin was quantified, and the amount of p38 and p53 was normalized to $ß$-actin.

Western blotting. After treatment, the cells were lysed, and protein concentrations were determined by the BCA assay using bovine serum albumin as a standard. The samples were loaded with $20 \mu \mathrm{g}$ and separated by electrophoresis on $10 \%$ SDS-polyacrylamide gels. After electrophoresis, the proteins were transferred to PVDF membranes in a Tris-glycine transfer buffer (48 mM Tris, $39 \mathrm{mM}$ glycine, $0.05 \% \mathrm{w} / \mathrm{v}$ SDS, $10 \% \mathrm{v} / \mathrm{v}$ methanol) using a semidry blotting system, detected with antibodies against phospho-p38, p53, and B-actin, and developed with ECL (Nanjing, Jiangsu, China). The intensity of each band was quantified utilizing the Fluor-s gel analyzing system and normalized to the band intensity of B-actin.

Statistical analysis. The statistical data are expressed as mean \pm SD. Statistical analysis was performed by one-way analysis of variance (ANOVA) and SNK-q. Differences were considered statistically significant at $\mathrm{P}<0.05$.

\section{Results}

Morphology and characterization of the rat chondrocytes. The primary chondrocytes were sphere-shaped with good refractivity in a diffused distribution in the culture flask just after seeding. After $24 \mathrm{~h}$, the cells started to adhere and were large square-shaped with filopodia. After 7 days, the cells gradually became isolated colonies, and the cells were spindleor polygonal-shaped with round nuclei. After 14 days, the chondrocytes underwent extensive proliferation, and the cells were confluent (Fig. 1A). After passage, the cells adhered to the bottom of the culture flasks after $24 \mathrm{~h}$, and after 7 days of culture, the cells became confluent in a single-cell layer. The passage 2 and 3 cells adopted a polygonal shape and were evenly distributed (Fig. 1B). After passage 4, the cells started to display an irregular shape and size. To characterize the isolated chondrocytes, cells were examined by in situ hybridization for type II collagen. The passage 2 chondrocytes were evenly distributed with a clear polygonal-shaped border, and the cytoplasm was stained brown-yellow, but the nuclear area was not stained (Fig. 1C). However, in the negative control group, the cytoplasm of the chondrocytes was not stained brown-yellow (Fig. 1D).

Optimization of the SNP concentration. To further confirm the morphological analysis, we examined the cells by staining with Hoechst 33342. As shown in Fig. 2A-H, the cell nuclei were round and stained light blue before treatment. There were significantly more dead cells in SNPtreated cells than in the control cells $(\mathrm{P}=0.001, \mathrm{P}=0.000)$, and the nuclei of apoptotic cells were condensed and bright blue. Chondrocytes treated with $2 \mathrm{mM}$ SNP underwent more apoptosis than those treated with $0.5 \mathrm{mM} \mathrm{SNP}(\mathrm{P}=0.000)$ and $1 \mathrm{mM}$ SNP $(\mathrm{P}=0.000)$. The cells treated with $1 \mathrm{mM}$ SNP showed more apoptosis than those treated with $0.5 \mathrm{mM} \mathrm{SNP}$ $(\mathrm{P}=0.000)$ (Table I). We chose to use the concentration of $1 \mathrm{mM}$ in the later experiments to induce apoptosis.

Millimeter wave treatment interfers with SNP-induced cell death. We tested the effect of the millimeter wave signal on the SNP-induced apoptosis by morphological analysis. The untreated cells (control group) showed no sign of apoptosis. The cells that received millimeter wave treatment (experimental group 2 and 3) showed fewer apoptotic cells than experimental group 1, and this same pattern was observed when Hoechst 33342 staining was used to analyze apoptosis (Fig. 3A-D). Quantification of the apoptosis in the individual groups is provided in Table II. Both experimental group 2 and 3 showed significantly less apoptosis compared with experimental group $1(\mathrm{P}=0.000, \mathrm{P}=0.000)$. A dose-dependent effect was evident as experimental group 3 , which received 

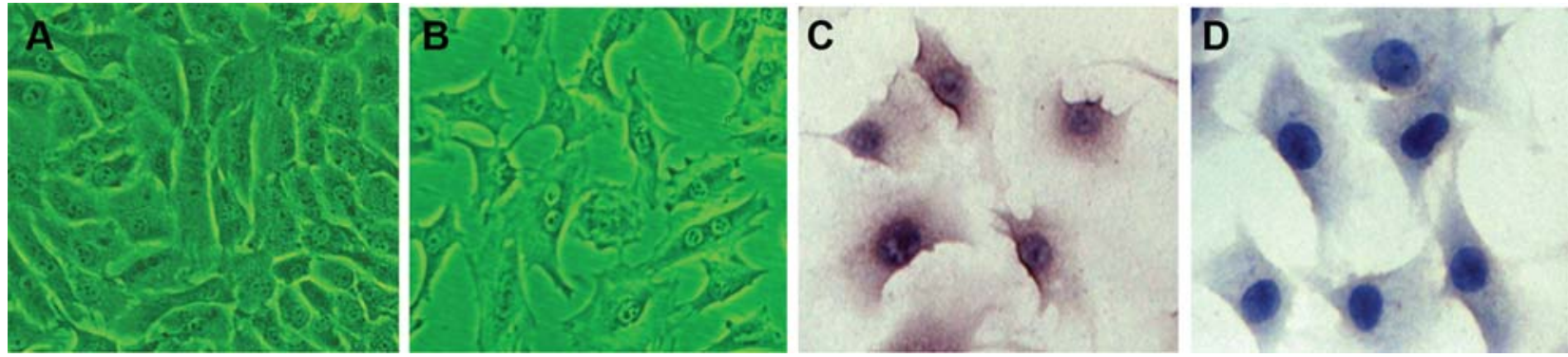

Figure 1. Culture and identification of chondrocytes in vitro (x200). (A) Primary generation chondrocytes cultured for 14 days, (B) second generation chondrocytes cultured for 3 days, (C) type II collagen in situ hybridization of the passage 2 cells cultured for 3 days and (D) negative control group, the passage 2 cells cultured for 3 days.
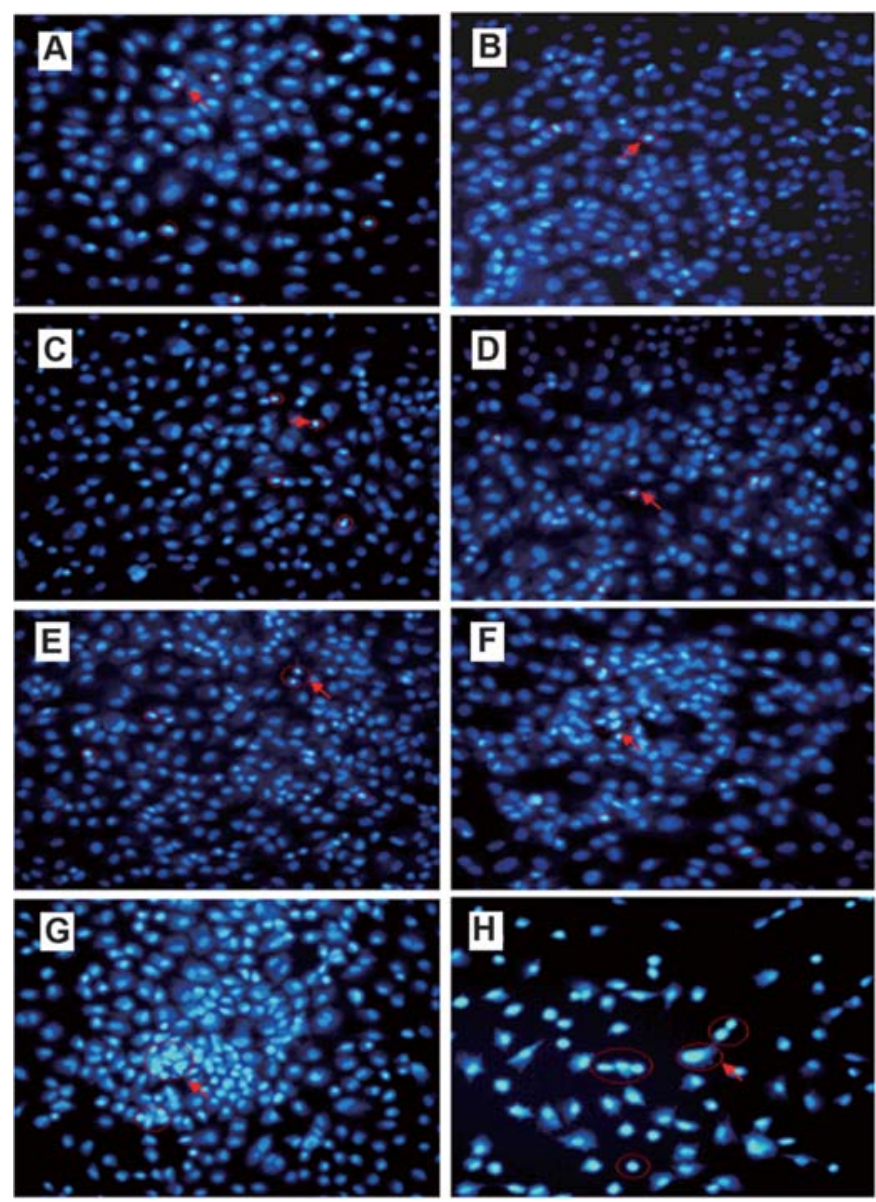

Figure 2. Hoechst 33342 staining of the chondrocytes (x100). Cells before treatment with (A) $0 \mathrm{mM}$, (B) $0.5 \mathrm{mM},(\mathrm{C}) 1 \mathrm{mM}$ and (D) $2 \mathrm{mM}$ SNP. Cells after treatment with (E) $0 \mathrm{mM},(\mathrm{F}) 0.5 \mathrm{mM},(\mathrm{G}) 1 \mathrm{mM}$ and $(\mathrm{H}) 2 \mathrm{mM} \mathrm{SNP}$ (arrows indicate apoptotic cells).

longer exposure to the millimeter wave signal, showed significantly increased apoptosis $(\mathrm{P}=0.018)$.

Cell survival was also measured using an MTT assay. Without treatment, there was no difference among the different groups, but after treatment, the OD values of the experimental groups were significantly lower than that of the control group $(\mathrm{P}=0.000)$. Notably, significantly fewer viable cells were noted in experimental group 3 compared with experimental group $1(\mathrm{P}=0.001)$ and $2(\mathrm{P}=0.021)$ (Table II).
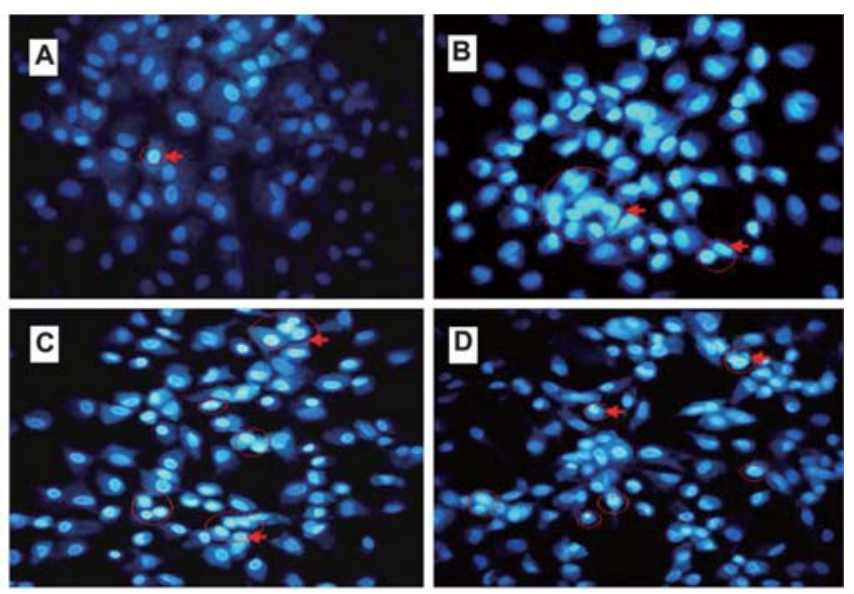

Figure 3. Microscopic analysis of the chondrocytes with SNP treatment and millimeter wave interference (x200). Hoechst 33342 staining of (A) control, (B) experimental group 1, (C) experimental group 2 and (D) experimental group 3 cells (arrows indicate apoptotic cells).

Table I. Dose dependency of SNP on apoptosis induction.

\begin{tabular}{lcc}
\hline Group & $\begin{array}{c}\text { Apoptotic rate } \\
\text { Before treatment }(\%)\end{array}$ & $\begin{array}{c}\text { Apoptotic rate } \\
\text { After treatment (\%) }\end{array}$ \\
\hline SNP $(0 \mathrm{mM})$ & $5.90 \pm 2.08$ & $6.20 \pm 2.34$ \\
SNP $(0.5 \mathrm{mM})$ & $6.10 \pm 2.28$ & $13.4 \pm 4.11^{\mathrm{a}}$ \\
SNP $(1 \mathrm{mM})$ & $5.80 \pm 1.93$ & $56.1 \pm 7.03^{\mathrm{a}, \mathrm{b}}$ \\
SNP $(2 \mathrm{mM})$ & $6.30 \pm 2.11$ & $91.1 \pm 5.02^{\mathrm{a}, \mathrm{b}, \mathrm{c}}$ \\
\hline
\end{tabular}

${ }^{\mathrm{a}} \mathrm{P}<0.01$ compared with SNP $(0 \mathrm{mM}),{ }^{b} \mathrm{P}<0.01$ compared with SNP $(0.5 \mathrm{mM})$ and ${ }^{\mathrm{c}} \mathrm{P}<0.01$ compared with $\mathrm{SNP}(1 \mathrm{mM})$.

Millimeter wave treatment antagonizes SNP-induced apoptosis. To further confirm that the cell death induced by SNP was apoptosis, FITC-Annexin V staining followed by FACS analysis was carried out. As shown in Fig. 4, the numbers of normal cells of the experimental groups were significantly lower than that of the control group $(\mathrm{P}=0.000)$, while the early apoptotic, late apoptotic, and dead cells were all significantly higher in number than those of the control 
Table II. Millimeter wave treatment interfers with SNP-induced apoptosis.

\begin{tabular}{|c|c|c|c|}
\hline \multirow[t]{2}{*}{ Group } & \multirow[t]{2}{*}{ Apoptosis rate $(\%)$} & \multicolumn{2}{|c|}{ MTT assay results for cell viability } \\
\hline & & OD without treatment & OD after treatment \\
\hline Control & $5.90 \pm 2.02$ & $0.58 \pm 0.05$ & $0.61 \pm 0.05$ \\
\hline Experimental 1 & $47.70 \pm 5.06^{\mathrm{a}}$ & $0.60 \pm 0.07$ & $0.27 \pm 0.06^{\mathrm{a}}$ \\
\hline Experimental 2 & $42.10 \pm 5.36^{\mathrm{a}, \mathrm{c}}$ & $0.57 \pm 0.06$ & $0.33 \pm 0.06^{\mathrm{a}}$ \\
\hline Experimental 3 & $32.90 \pm 6.57^{\mathrm{a}, \mathrm{b}, \mathrm{d}}$ & $0.59 \pm 0.05$ & $0.42 \pm 0.07^{\mathrm{a}, \mathrm{b}, \mathrm{c}}$ \\
\hline
\end{tabular}

${ }^{\mathrm{a}} \mathrm{P}<0.01$ compared with the control group, ${ }^{\mathrm{b}} \mathrm{P}<0.01$ compared with experimental group $1,{ }^{\mathrm{c}} \mathrm{P}<0.05$ compared with experimental group 1 and ${ }^{\mathrm{d}} \mathrm{P}<0.01$ compared with experimental group 2 .

Table III. Apoptotic rate detected using FACS.

\begin{tabular}{lcccc}
\hline Group & Normal & Early apoptosis & Late apoptosis & Dead cell \\
\hline Control & $95.61 \pm 1.92$ & $2.47 \pm 1.21$ & $1.26 \pm 0.58$ & $0.66 \pm 0.44$ \\
Experimental 1 & $54.05 \pm 4.62^{\mathrm{a}}$ & $16.55 \pm 1.69^{\mathrm{a}}$ & $18.51 \pm 2.64^{\mathrm{a}}$ & $10.89 \pm 1.66^{\mathrm{a}}$ \\
Experimental 2 & $63.35 \pm 4.74^{\mathrm{a}, \mathrm{b}}$ & $14.56 \pm 2.69^{\mathrm{a}}$ & $12.55 \pm 2.58^{\mathrm{a}, \mathrm{b}}$ & $9.54 \pm 1.91^{\mathrm{a}}$ \\
Experimental 3 & $78.19 \pm 3.57^{\mathrm{a}, \mathrm{b}, \mathrm{c}}$ & $9.92 \pm 1.62^{\mathrm{a}, \mathrm{b}, \mathrm{c}}$ & $8.74 \pm 1.70^{\mathrm{a}, \mathrm{b}, \mathrm{c}}$ & $3.15 \pm 1.05^{\mathrm{a}, \mathrm{b}, \mathrm{c}}$ \\
\hline
\end{tabular}

${ }^{\mathrm{a}} \mathrm{P}<0.01$ compared with the control group, ${ }^{\mathrm{b}} \mathrm{P}<0.01$ compared with experimental group $1,{ }^{\mathrm{c}} \mathrm{P}<0.01$ compared with experimental group 2 .
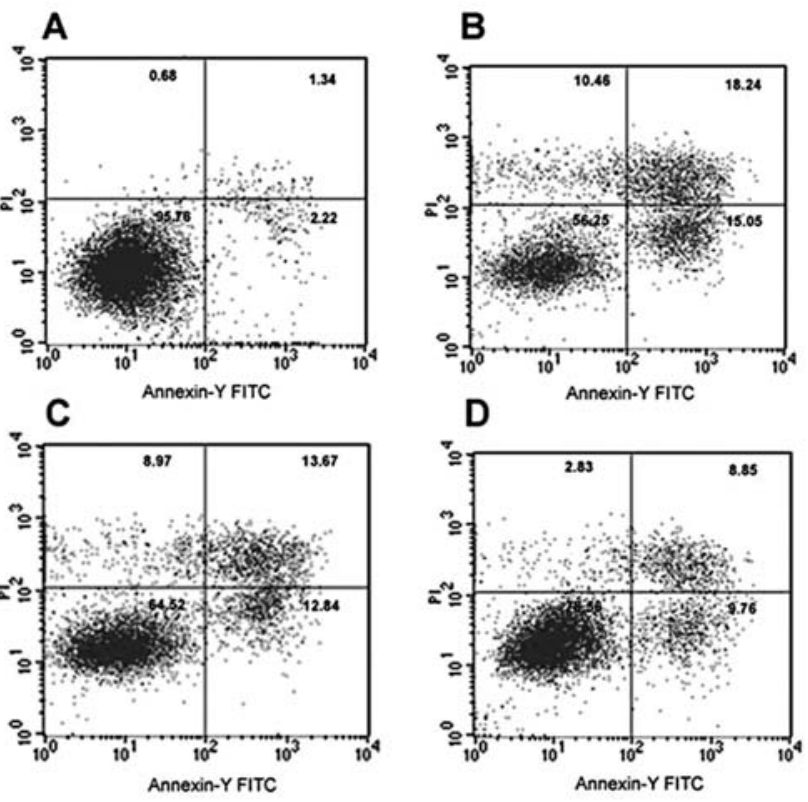

Figure 4. FACS analysis of the chondrocytes with SNP treatment and millimeter wave interference. (A) Control, (B) experimental group 1, (C) experimental group 2 and (D) experimental group 3 cells. In the panels, the cells in the lower-left corner are the normal cells; the cells in the right-lower corner are the early apoptotic; the cells in the right-upper corner are late apoptotic; and the cells in the left-upper corner are dead cells.

group. Following treatment with a millimeter wave (experimental group 2 and 3), the proportion of early apoptotic, late apoptotic, and dead cells all decreased, and there was a dose- dependency of the millimeter wave treatment (Table III). These results are consistent with previous studies demonstrating that SNP treatment can lead to cell apoptosis. Notably, the millimeter wave treatment antagonized the pro-apoptotic effect of SNP.

The activity of caspase-3 was also measured. After SNP treatment, the caspase- 3 activity in the experimental groups was significantly higher than in the control group $(\mathrm{P}=0.000$, $\mathrm{P}=0.008$ ). The caspase- 3 activity of experimental group 3 was significantly lower than that of experimental group 1 $(\mathrm{P}=0.001)$ and $2(\mathrm{P}=0.018)$ (Table IV).

Millimeter wave signal regulates expression and activation of p38 and p53. To further explore the mechanism of the millimeter wave signal, we analyzed the expression and activity levels of p38 and p53. The mRNA expression of p38 and p53 was first detected using RT-PCR. As shown in Fig. 5, the amplified products of 275 bp for p38 and 232 bp for p53 were clearly visible on the agarose gel. Quantification of the PCR products indicated that the levels of $\mathrm{p} 38$ and p53 were significantly higher in the experimental groups than in the control group $(\mathrm{P}=0.000, \mathrm{P}=0.007 ; \mathrm{P}=0.000$, $\mathrm{P}=0.001)$. The levels of $\mathrm{p} 38$ and $\mathrm{p} 53$ in experimental group 3 were also significantly lower than in experimental groups 1 $(\mathrm{P}=0.000, \mathrm{P}=0.000)$ and $2(\mathrm{P}=0.000, \mathrm{P}=0.012)$ (Table IV).

The protein expression of p38 and p53 was also detected using Western blotting. As shown in Fig. 6, quantification of the Western blotting bands showed that the levels of phospho-p38 and p53 protein were significantly higher in the experimental groups than in the control group $(\mathrm{P}=0.000$, $\mathrm{P}=0.000)$. The protein levels of phospho-p38 and p53 in 
Table IV. Caspase-3, p38 and p53 expression in chondrocytes of the different experimental groups.

\begin{tabular}{|c|c|c|c|c|c|}
\hline \multirow[b]{2}{*}{ Group } & \multirow[b]{2}{*}{ Caspase-3 activity $(\mu \mathrm{g} / \mu \mathrm{l})$} & \multicolumn{2}{|c|}{ RT-PCR } & \multicolumn{2}{|c|}{ Western blot analysis } \\
\hline & & p38 mRNA & p53 mRNA & Phosphor-p38 & p53 \\
\hline Control & $0.59 \pm 0.16$ & $0.17 \pm 0.06$ & $0.29 \pm 0.08$ & $0.15 \pm 0.03$ & $0.16 \pm 0.04$ \\
\hline Experimental 1 & $3.24 \pm 0.77^{\mathrm{a}}$ & $0.54 \pm 0.05^{\mathrm{a}}$ & $0.62 \pm 0.04^{\mathrm{a}}$ & $0.65 \pm 0.08^{\mathrm{a}}$ & $0.55 \pm 0.06^{\mathrm{a}}$ \\
\hline Experimental 2 & $2.55 \pm 0.64^{\mathrm{a}}$ & $0.47 \pm 0.07^{\mathrm{a}, \mathrm{c}}$ & $0.55 \pm 0.06^{\mathrm{a}}$ & $0.56 \pm 0.06^{\mathrm{a}, \mathrm{c}}$ & $0.53 \pm 0.07^{a}$ \\
\hline Experimental 3 & $1.64 \pm 0.67^{\mathrm{a}, \mathrm{b}, \mathrm{e}}$ & $0.27 \pm 0.04^{\mathrm{a}, \mathrm{b}, \mathrm{d}}$ & $0.44 \pm 0.07^{\mathrm{a}, \mathrm{b}, \mathrm{e}}$ & $0.47 \pm 0.07^{\mathrm{a}, \mathrm{b}, \mathrm{e}}$ & $0.45 \pm 0.07^{\mathrm{a}, \mathrm{c}, \mathrm{e}}$ \\
\hline
\end{tabular}

${ }^{\mathrm{a}} \mathrm{P}<0.01$ compared with the control group, ${ }^{\mathrm{b}} \mathrm{P}<0.01$ compared with experimental group $1,{ }^{\mathrm{c}} \mathrm{P}<0.05$ compared with experimental group 1 , ${ }^{\mathrm{d}} \mathrm{P}<0.01$ compared with experimental group 2 and ${ }^{\mathrm{e}} \mathrm{P}<0.05$ compared with experimental group 2 .

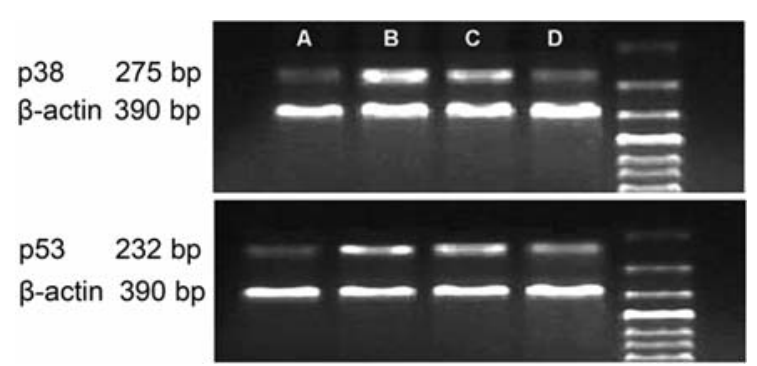

Figure 5. RT-PCR amplification of p38 and p53 from treated passage 2 chondrocytes. (A) Control, (B) experimental group 1, (C) experimental group 2 and (D) experimental group 3 cells.

experimental group 3 were also significantly lower than in experimental groups $1(\mathrm{P}=0.000, \mathrm{P}=0.013)$ and $2(\mathrm{P}=0.023$, $\mathrm{P}=0.040)$. In addition, the phospho-p38 level in experimental group 2 was significantly lower than that in experimental group $1(\mathrm{P}=0.030)$ (Table IV).

\section{Discussion}

Joint cartilage is composed of chondrocytes and extracellular matrix. Mechanical and chemical isolation methods have been established through which the primary chondrocytes can be isolated and maintained by passage culture. Our study showed that the nucleus of the chondrocytes was positive in the in situ hybridization of type II collagen while the cytoplasm was negative. With the culture time elongation, the expression of type II collagen gradually decreased. These results suggest that the cells that we isolated were chondrocytes and that the cellular features were mostly maintained within passage 2-3. Therefore, the passage 2 chondrocytes were used in the subsequent experiments.

NO can be induced by cellular oxygen metabolism and the oxidative respiratory chain under inflammatory stimuli or in the presence of exogenous donors such as SNP and NOC. Here we used SNP to induce apoptosis and observed a dosedependent apoptosis induction. Hoechst 33342 staining showed that the apoptotic rate was $56.1 \pm 7.03 \%$ in the presence of $1 \mathrm{mM} \mathrm{SNP}$, and this condition was used in the following experiments. After millimeter wave treatment, the SNPinduced apoptosis was significantly inhibited, and longer treatment showed better effects. FACS analysis is more

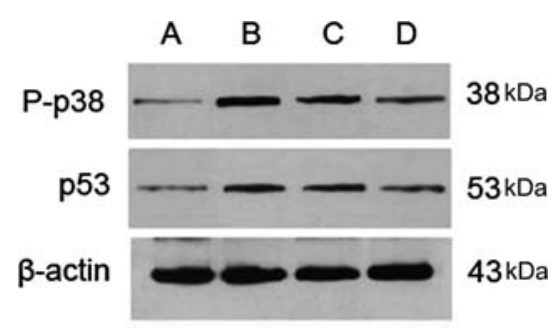

Figure 6. Western blotting of phospho(P)-p38 and p53 from experimental treated passage 2 chondrocytes. (A) Control, (B) experimental group 1, (C) experimental group 2 and (D) experimental group 3 cells.

sensitive in detecting apoptotic cells than the MTT assay, and our FACS results showed that the millimeter wave treatment significantly decreased the proportion of early apoptotic, late apoptotic, and dead cells and increased the proportion of normal cells, suggesting that the millimeter wave signal may inhibit the apoptosis of chondrocytes.

Under normal conditions, the protein level of p38 in certain tissues is relatively stable. However, p38 can be activated by multiple stimuli, including inflammatory factors, and the phosphorylated form of p38 represents the active state $(16,17)$. When extracellular stimuli were applied to the cells, the cytoplasmic p38 was phosphorylated and translocated to the nucleus to activate transcription factors and promote downstream gene expression to promote apoptosis. Activation of $\mathrm{p} 38 \mathrm{MAPK}$ leads to the phosphorylation of serine 33 and serine 46 of the p53 protein. There are two ways for p53 protein to promote apoptosis (18). One is through enhancing production of the apoptotic protein that releases cytochrome $\mathrm{C}$ from mitochondria and eventually leads to caspase- 3 activation and apoptosis. The second way is through production and activation of the cell surface death receptors. Blocking p38MAPK activation can decrease the phosphorylation of serine 33,34 , and 15 therefore inhibiting apoptosis. In addition, p38MAPK can also regulate caspase-3. The phosphorylation and activation of p38MAPK may cause the release of cytochrome $\mathrm{C}$ and activation of caspase- 3 and may initiate the cascade of apoptosis $(19,20)$. There are three stages of chondrocyte apoptosis, the most important of which is the executive stage (21), with caspase-3 as the key executive enzyme. Under normal states, cytoplasmic caspase-3 exists as an inactive pro-enzyme and is only activated when 
apoptosis occurs. Caspase-3 can cleave ADP-ribose polymerase (PARP) to activate the nucleus endonuclease, which then cuts DNA between nucleosomes. Meanwhile, caspase-3 also cleaves lamin A protein to disrupt the nuclear network, condense the nucleosomes and cause apoptosis $(22,23)$. Preventing the activation of p38MAPK can inhibit the phosphorylation of p53 and activation of p38 and p53 and inhibit the apoptosis of chondrocytes. This study indicated that a millimeter wave can prevent the SNP-induced apoptosis of chondrocytes probably by inhibiting mRNA expression or the phosphorylation of $\mathrm{p} 38$ and $\mathrm{p} 53$, together with a decrease in the enzyme activation of caspase- 3 .

Here, our study showed that radiation using a millimeter wave signal with a wavelength of 7.5-10.0 $\mathrm{mm}$ and power density of $4 \mathrm{Mw} / \mathrm{cm}^{2} 3$ times per day for $30 \mathrm{~min}$ or $60 \mathrm{~min}$ can inhibit SNP-induced chondrocyte apoptosis. Furthermore, 60 min of radiation showed better effects to counteract SNPinduced apoptosis compared to $30 \mathrm{~min}$ of radiation. The underlying mechanism may involve the regulation of the activation and expression of $\mathrm{p} 38$, decrease in the expression of p53, and inhibition of the executive caspase- 3 by the millimeter wave signal, thereby blocking the apoptotic process of chondrocytes. However, our findings in this study were limited to the inhibitory effect of a millimeter wave on SNP-induced apoptosis. Whether a millimeter wave can inhibit osteoarthritis or the natural apoptosis of chondrocytes remains to be verified.

\section{Acknowledgements}

This study was supported by the Research Foundation of the Education Bureau of Fujian Province (grant no. JA07113); Project supported by the Laboratory of Optical Physics, Institute of Physics, Chinese Academy of Sciences, China (grant no. 2008J1004-16).

\section{References}

1. Johnson EO, Charchandi A, Babis GC and Soucacos PN: Apoptosis in osteoarthritis: morphology, mechanisms, and potential means for therapeutic intervention. J Surg Orthop Adv 17: 147-152, 2008

2. Saito S, Murakoshi K, Kotake S, Kamatani N and Tomatsu T: Granzyme B induces apoptosis of chondrocytes with natural killer cell-like cytotoxicity in rheumatoid arthritis. J Rheumatol 35: 1932-1943, 2008.

3. Dave M, Attur M, Palmer G, Al-Mussawir HE, Kennish L, Patel J and Abramson SB: The antioxidant resveratrol protects against chondrocyte apoptosis via effects on mitochondrial polarization and ATP production. Arthritis Rheum 58: 2786-2797, 2008.

4. Ding L, Guo D and Homandberg GA: The cartilage chondrolytic mechanism of fibronectin fragments involves MAP kinases: comparison of three fragments and native fibronectin. Osteoarthritis Cartilage 16: 1253-1262, 2008.

5. Andjelkov N, Elvenes J, Knutsen G and Johansen O: Betaendorphin regulation of MAPKs in cultured human articular chondrocytes: MAPK inhibitors prevent the increase of IL-1 beta protein levels during beta-endorphin stimulation. Cell Commun Adhes 14: 1-8, 2007.
6. Hamamura K, Goldring MB and Yokota H: Involvement of p38 MAPK in regulation of MMP13 mRNA in chondrocytes in response to surviving stress to endoplasmic reticulum. Arch Oral Biol 54: 279-286, 2009.

7. Namdari S, Wei L, Moore D and Chen Q: Reduced limb length and worsened osteoarthritis in adult mice after genetic inhibition of p38 MAP kinase activity in cartilage. Arthritis Rheum 58: 3520-3529, 2008.

8. Zaman F, Menendez-Benito V, Eriksson E, et al: Proteasome inhibition up-regulates p53 and apoptosis-inducing factor in chondrocytes causing severe growth retardation in mice. Cancer Res 67: 10078-10086, 2007.

9. Iannone F, De Bari C, Scioscia C, Patella V and Lapadula G: Increased Bcl-2/p53 ratio in human osteoarthritic cartilage: a possible role in regulation of chondrocyte metabolism. Ann Rheum Dis 64: 217-221, 2005.

10. Shakibaei M, John T, Seifarth C and Mobasheri A: Resveratrol inhibits IL-1 beta-induced stimulation of caspase- 3 and cleavage of PARP in human articular chondrocytes in vitro. Ann NY Acad Sci 1095: 554-563, 2007.

11. Millenbaugh NJ, Roth C, Sypniewska R, et al: Gene expression changes in the skin of rats induced by prolonged $35 \mathrm{GHz}$ millimeter-wave exposure. Radiat Res 169: 288-300, 2008.

12. Zhadobov M, Sauleau R, Le Coq L, Debure L, Thouroude D, Michel D and Le Drean Y: Low-power millimeter wave radiations do not alter stress-sensitive gene expression of chaperone proteins. Bioelectromagnetics 28: 188-196, 2007.

13. Szabo I, Kappelmayer J, Alekseev SI and Ziskin MC: Millimeter wave induced reversible externalization of phosphatidylserine molecules in cells exposed in vitro. Bioelectromagnetics 27: 233-244, 2006.

14. Wu GW, Liu XX, Wu MX, Zhao JY, Chen WL, Lin RH and Lin JM: Experimental study of millimeter wave-induced differentiation of bone marrow mesenchymal stem cells into chondrocytes. Int J Mol Med 23: 461-467, 2009.

15. Tonomura $\mathrm{H}$, Takahashi KA, Mazda O, et al: Glutamine protects articular chondrocytes from heat stress and NO-induced apoptosis with HSP70 expression. Osteoarthritis Cartilage 14: 545-553, 2006.

16. Iwai T, Murai J, Yoshikawa H and Tsumaki N: Smad7 inhibits chondrocyte differentiation at multiple steps during endochondral bone formation and down-regulates p38 MAPK pathways. J Biol Chem 283: 27154-27164, 2008.

17. Stanton LA and Beier F: Inhibition of p38 MAPK signaling in chondrocyte cultures results in enhanced osteogenic differentiation of perichondral cells. Exp Cell Res 313: 146-155, 2007.

18. Okazaki R, Sakai A, Ootsuyama A, Sakata T, Nakamura T and Norimura T: Apoptosis and p53 expression in chondrocytes relate to degeneration in articular cartilage of immobilized knee joints. J Rheumatol 30: 559-566, 2003.

19. Van Laethem A, Van Kelst S, Lippens S, et al: Activation of p38 MAPK is required for Bax translocation to mitochondria, cytochrome c release and apoptosis induced by UVB irradiation in human keratinocytes. FASEB J 18: 1946-1948, 2004.

20. Wang $\mathrm{H}$, Wang $\mathrm{Z}$, Chen $\mathrm{J}$ and $\mathrm{Wu} \mathrm{J}$ : Apoptosis induced by NO via phosphorylation of p38 MAPK that stimulates NF-kappaB, p53 and caspase- 3 activation in rabbit articular chondrocytes. Cell Biol Int 31: 1027-1035, 2007.

21. Del Carlo M Jr and Loeser RF: Cell death in osteoarthritis. Curr Rheumatol Rep 10: 37-42, 2008.

22. Watrin-Pinzano A, Etienne S, Grossin L, et al: Increased apoptosis in rat osteoarthritic cartilage corresponds to degenerative chondral lesions and concomitant expression of caspase-3. Biorheology 43: 403-412, 2006.

23. Shakibaei M, Schulze-Tanzil G, John T and Mobasheri A: Curcumin protects human chondrocytes from IL-1beta-induced inhibition of collagen type II and beta1-integrin expression and activation of caspase-3: an immunomorphological study. Ann Anat 187: 487-497, 2005. 